during 1984, there were 455 individual osteopathic physicians and basic scientists who were either the primary investigator or a collaborator in the activity. Of the 455,193 were D.O.s, but only 101 of these were listed as the principal investigator. Also, the vast majority of projects performed by Ph.D. researchers in osteopathic institutions were funded by federal agencies, whereas the majority of funding for clinicians was through in-house support and from pharmaceutical houses.

Clearly, there is a need to increase the number of clinicians who will be prepared to conduct or participate in medical research. The efforts of several of our colleges of osteopathic medicine to develop physician-scientist programs that combine the D.O. and Ph.D. degrees should be encouraged and supported. Additional suggestions for increasing the number of clinician-scientists are proposed by D'Alonzo; they bear close reading and attention.

THOMAS W. ALLEN, D.O., FACOI

1. Northup, G.W., ed.: Osteopathic research. Growth and development. American Osteopathic Association, Chicago, 1987

\section{The erosion of medicine}

We live in an era where positive and forward thinking are popular things. But in order to achieve positive results, we sometimes have to look backwards to determine a dynamic purpose for the future.

It is useful once in a while to stop and think about terms. The word "medicine," for example, has at least three definitions: It refers to any drug or remedy; to the art and science of the diagnosis and treatment of disease and the maintenance of health; and to the treatment of disease by nonsurgical means.

Certainly that broad definition has been generally accepted throughout the ages. But the unique responsibility of physicians to adhere to such a definition is being eroded and narrowed by recent advances. In no way is this meant to be critical of groups of sincere individuals who are trying to advance their cause. But at the same time, physicians should be aware of what is happening.

For example, several states throughout the country have enacted legislation permitting physical therapists to accept patients without prior medical referral. In many of these states, the legislation's impact was not studied to any extent. Of course, on the one hand, it increased the vulnerability of the physical therapist in accepting responsibility for making a diagnosis. It also increased their profes- sional liability. But it was taken to extremes when some state boards of physical therapy began sending notices to physicians who use physical therapy modalities in their offices. They were told that they should stop using such modalities because they were practicing physical therapy without a license. Also interesting to note is that the same group is promoting courses in manipulative therapy. Could it be that same group who tried to get legislative sanction saying that manipulative therapy is a physical therapy modality only, and that it should be restricted to and licensed only by physical therapists?

Another development is the suggestion of clinical pharmacists that they be allowed greater authority in the pharmacologic management of, in particular, hospital inpatients. In some instances, they wish to have a deciding role in the selection and prescription of medications to be administered.

Before we become too critical, let us look back in history a bit and see what has happened in a couple of other areas. At least two professions have developed primarily due to a lack of interest on the part of medicine in that particular area of practice. For example, podiatrists largely filled the void created by general practitioners and some orthopedic surgeons who weren't particularly interested in disorders of the feet. And optometry developed when a number of ophthalmologists weren't too interested in refraction, and focused more concern towards eye surgery and ocular diseases. Both the podiatrists and the optometrists are constantly trying to seek legislation which would widen their turf. However, it is to their credit that they have never done anything to seek restrictive legislation that would protect their health care domain by a wall of exclusiveness.

The erosion is taking place now. And whether D.O. or M.D., our traditional turf is gradually being eroded. We need to be acutely aware of what's going on and develop programs to stop it.

GEORGE W. NORTHUP, D.O., FAAO

\section{$\overline{\text { editorial comment }}$}

\section{Health maintenance organizations (HMOs)} have failed to reduce per capita hospital costs in the nation's major cities, according to a University of Michigan study.

As participation in HMOs rises in a major metropolitan area, so does the average cost of hospital continued on page $409 / 68$ 
ESCRIPTION: Eoch milliliter of ASALCROMः (cromolyn sodium asol solution, USP) contains $40 \mathrm{mg}$ romolyn sodium in purtied water Th berzolkonium chloride $0.01 \%$ ind . NDICANONS: NASALCROM is indiyoded for the prevention and tredtment ff the symptoms of allergic minitis. CONTRANDICATIONS: NASALCROM s contraindicated in those patients who have shown hypersensitivity to any of the ingredients.

PRECAUTIONS: Generol: SOMe pothe tents may expenence flansient nosal stinging and/or sneezing immedidtely bilowing instilition of NASALCROM. Except in rore cocurrences, these expeniences hove hol coused discontinu ation of theropy.

in view of the biliary and renal routes of excretion for cromolyn sodium, consideration should be given to decreas. ing the dosoge or discontinuing the odministrotion of the drug in patients with impoined renal or hepctic function. Cosing Carcinogenesis, Mutogenesis, anc Impoirment of Fertility: Long term studies in mice ( 12 monitins intrioperito neal treatiment followed by 6 months observation), hamsters (12 months intraperitioneal treatment followed by 12 months observation), and rats (18 months subcutaneous trediment) showed no neoplastic effect of cromolyn sodium.

No evidence of chromosomal damage or cylotoxicity was obtained in various mulogenesis studies

No evidence of impoired fertility was shown in laboratory animal reproduc tion studies.

Pregnancy: Pregnancy Category B. Reproduction studies with cromoly sodium administered parenterally to pregnant mice, rots, and robbits in doses up to 338 times the human clin icl doses produced no evidence 0 tol mollormations. Adverse for challo lects (inciecsed resorplions and de creased letal weighin) Were noled only of the very high porenteral doses the produced maternal toxicily There are however, no odequde and wel controlled studies in pregnant womer Because animal reproduction studie are not always predictive of human re sponse, this drug should be used du ing preanancy only if clearly needed Drug Interoction During Pregnancy: Cromolyn sodium and isoprotereno were studied following subcutaneous iniections in pregnant mice. Cromolyn injections in pregnanim mee 60 to 540 socium alone in 338 fimes the human mg/kg (38 to 338 times the human dose) did not couse significant increases in resorptions or major moflor mations. isoproterenol alone at a dose of $2.7 \mathrm{mg} / \mathrm{kg}$ (90 times the human dose) increased both resoptions and malformations. The oddition of cromoIyn sodium ( 338 times the human dose) to isoproterenol (90 times the human dose) appears to have incresed the incidences of both resorptions and moltormations.

Nursing Mothers: It is not known Whether this drug is excreled in human milk Becouse many drugs are excreted in human milk caution should be exercised When NASALCROM is odministered to a nursing woman. Pediatric Use: Soltely and effectiveness in children below the age of 6 Yeors have not been established. ADVERSE REACTIONS: The most treAOVent odverse reoctions occurring in quent odverse reactions occurring in the 430 potients included in the cinical tials with NASALCROM were sneezing (1 in 10 palients), nase stinging (1 in 20), nosal burning in 25), and nasal irrtianon (in 40 ). Heodoches and 100 instients. Epi. staxis postnosol drip, and rosh were reported in less than one percent to

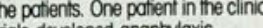
thals developed anaphylaxis

Adverse reoctions which have $\infty$ curred in the use of other cromolyn sodium tormulations for intalation in clude angioedema, joint pain and swelling, urticana, cough, and wheezing. Other reactions reported farely are serum sickness, penartertic voscullis, polymiositis periogritis, photodermattis, extoliative dermatitis, peripheral neuritis, and nephrosis. NASALCROM" is a registered trodemark of Fisons plc.

\section{"I LIKE HOW FAST IT WORKS TO STOP MY ALLERGIES, WITHOUT MAKING ME DROWSY."}

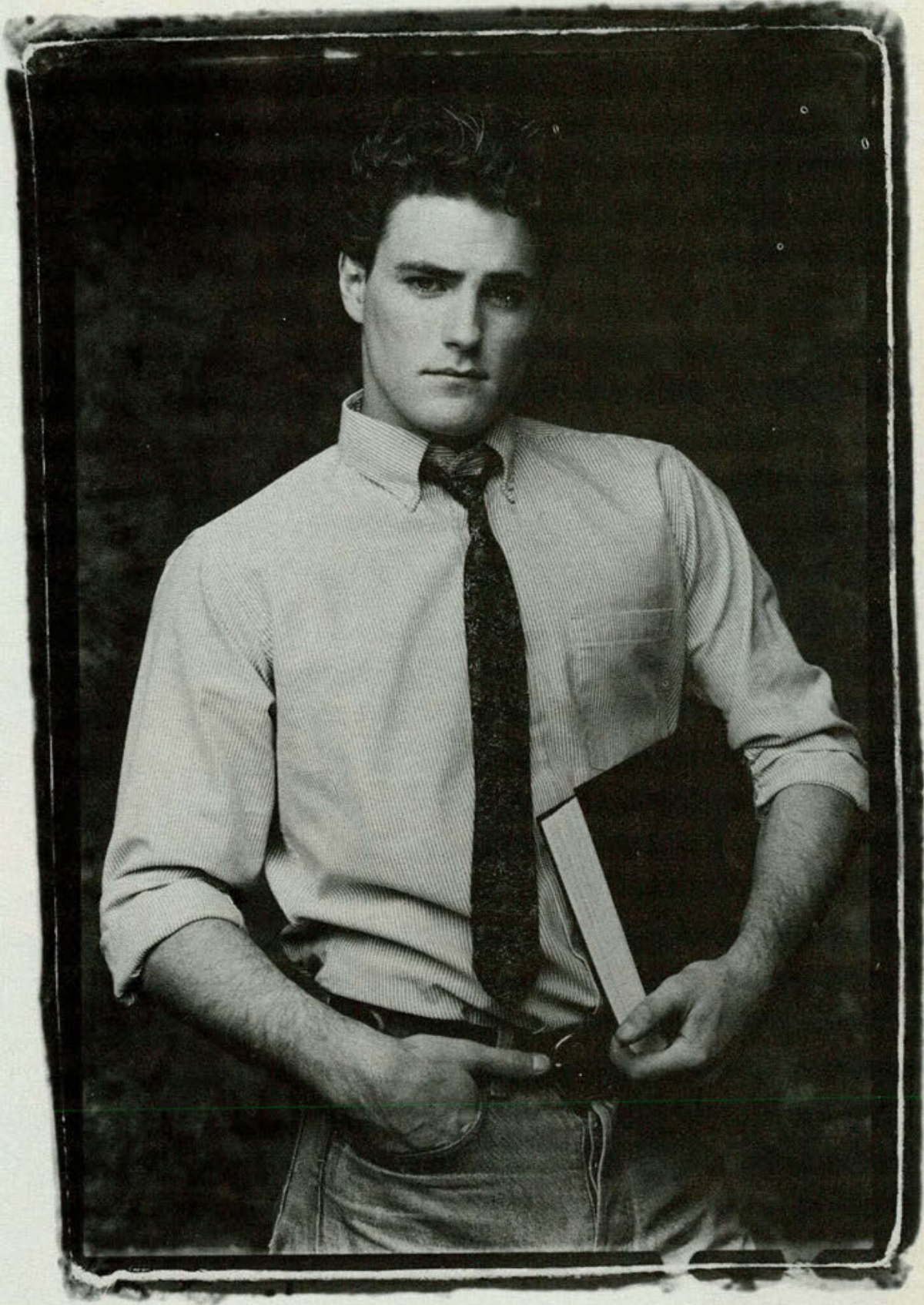

NASALCROM works rapidly-usually within the first few doses-to relieve the congestion, rhinorrhea, and sneezing of seasonal allergic rhinitis. However, for many patients, the side effects of traditional medications can be as troublesome as the allergic symptoms themselves. Unlike these medications, NASALCROM is extremely well-tolerated therapy, virtually uncomplicated by serious side effects, tolerance or contraindications.

\section{NASALCROM (cromolyn sodium/FISONS)}

Stops allergic rhinitis rapidly, without traditional side effects 

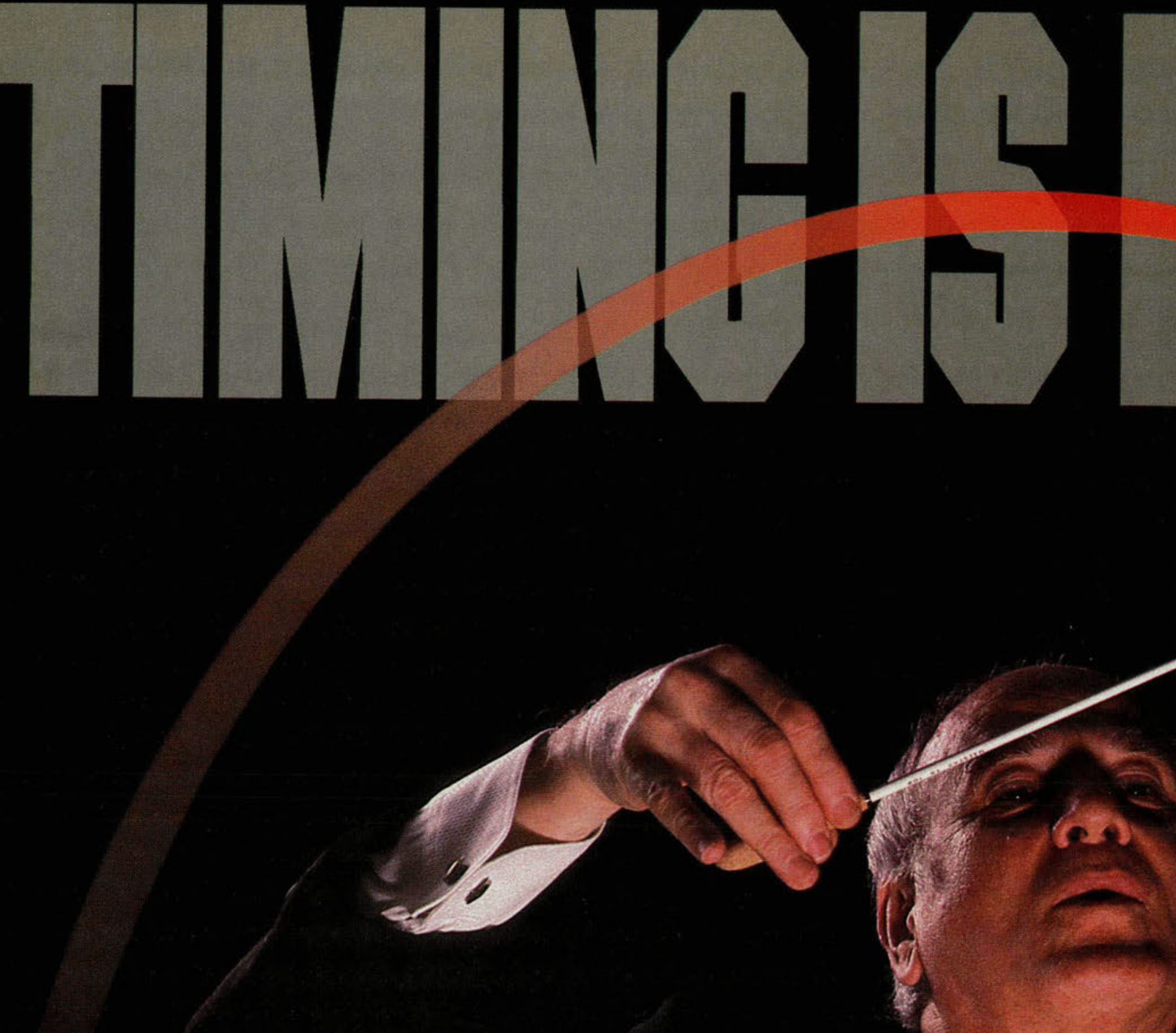

(w) $(\mathrm{ar})$
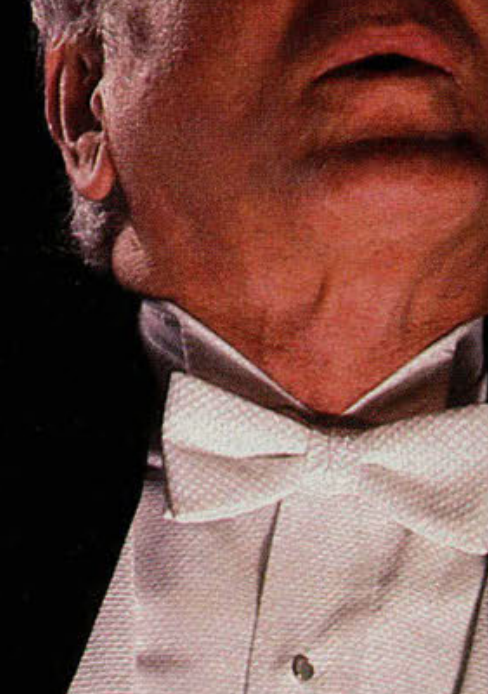

0

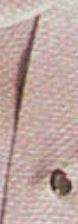


Reterence:

1. Sachs R, Frank M Fishman SK: Overview of clinical experience with glipizide, in Glipizide: A Worldwide Review Princeton, NJ. Excerpta Medica, 1984, pp 163-172

GLUCOTROL (glipizide) Tablets

\section{Brief Summary of Prescribing Information}

INOICATIONS AND USAGE: GLUCOTROL is indicated as an adjunct to diet for the control of hyperglycemia in patients with non-insul

CONTRAINDICATIONS: GLUCOTROL is contraindicated in patients with known hypersensitivity to the drug or with diabetic ketoacidosis, with or without coma, which should be treated with insulin

SPECIAL WARNING ON INCREASED RISK OF CARDIOVASCULAR MORTALITY: The administration of oral hypoglycemic drugs has been reported to be associated with increased cardiovascular mortality as compared to treatment with diet alone or diet plus insulin. This warning is based on the study conducted by the University Group Diabetes Program (UGDP), a long-term prospective clinical trial designed to evaluate the effectiveness glucose-lowering drugs in preventing or delaying vascular complications in patients with non-insulin-dependent diabetes. The study involved 823 patients who were randomly assigned to one of tour treatment groups (Oiabetes 19. supp. 2:747-830, 1970

UGDP reported that patients treated for 5 to 8 years with diet plus a fixed dose of tolbutamide (1.5 grams per day)

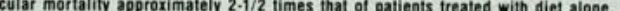
significant increase in total mortal ty was not observed, but the use of tolbutamide was discontinued based on the increase in cardiovascular mortality, thus limiting the opportunity for the study to show an increase in overall mortality. Despite controversy regarding the interpretation of these results, the findings of the UGDP stud provide an adequate basis for this warning. The patient should be informed of the potential risks and advantages of GLUCOTROL and of alternative modes of therapy.

Although only one drug in the sulfonylurea class (tolbutamide) was included in this study, it is prudent from a satety standpoint to consider that this warning may also apply to other oral hypoglycemic drugs in this class. in view of their close similarities in mode of action and chemical structure.

PRECAUTIONS: Renal and Hepatic Disease: The metabolism and excretion of GLUCOTROL may be slowed in patients with impaired renal and/or hepatic function. Hypoglycemia may be prolonged in such patients should it occut: Hypoglycemia: All sulfonylureas are capable of producing severe hypoglycemia. Proper patient selection, dosage and instructions are important to avoid hypogiycemia. Renal or hepatic insutticiency may increase the risk of hypoglycemic reactions. Elderly. debilitated, or malnourished patients and those with adrenal or pifuitary insutficiency are particularly susceptible to the hypoglycemic action of glucose-lowering drugs. Hypoglycemia may be difficult io recognize in the elderly or people taking beta-adrenergic blocking drugs. Hypoglycemia is more likely to occur when caloric intake is deficient, after severe or prolonged exercise, when alcohol is ingested. or when more than one glucose-lowering drug is used.

Loss of Control of Blood Glucose: A loss of control may occur in diabetic patients exposed to stress such as feve; trauma. infection or surgery. It may then be necessary to discontinue GLUCOTROL and administer insulin. Laboratory Tests: Blood and urine glucose should be monitored periodically. Measurement of glycosylated hemoglobin may be useful.

Information for Palients: Patients should be informed of the potential risks and advantages of GLUCOTROL, of alternative modes of therapy. as well as the importance of achering to dietary instructions, of a regular exercise program, and of regular testing of urine and or blood glucose. The risks of hypoglycemia, its symptoms and treatment, and conditions that predispose to its development should be explained to patients and responsible family members. Primary and secondary failure should also be explained.

Orug Interactions: The hypoglycernic action of sulfonylureas may be potentiated by certain drugs including non. steroidal anti-inflammatory agents and other drugs that are highly protein bound. salicylates, sulfonamides. chiloramphenicol, probenecid, coumarins, monoamine oxidase inhibitors, and beta adrenergic blocking agents. In vitro studies indicate that GLUCOTROL binds differently than tolbutamide and does not interact with salicylate or dicumarol. However, caution must be exercised in extrapolating these findings to a clinical situation. Certain drugs tend to produce hypergiycemia and may lead to loss of control, including the thiazides and other diuretics, corticosteroids.

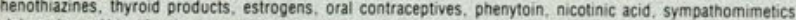
calcium channei blocking drugs, and isoniazid. A potential interaction between oral miconazole and oral hypoglycemic agents leading to severe hypoglycemia has been reported. Whether this interaction also occurs with the intravenous. lopical. or vaginal preparations of miconazole is not known.

Carcinogenesis, Mutagenesis. Impairment of Fertility: A 20-month study in rats and an 18-month study in mice at doses up to 75 times the maximum human dose revealed no evidence of drug-related carcinogenicity. Bacterial and in vivo mutagenicity tests were uniformly negative. Studies in rats of both sexes at doses up to 75 times the human dose Pregnancy Pregn on tertinty

Pregnancy: Pregnancy Category C: GLUCOTROL (glipizide) was found to be mildiy fetotoxic in rat reproductive studies at all dose levels $(5-50 \mathrm{mg} / \mathrm{kg})$. This fetotoxicity has been similarly noted with other sulfonylureas, such as colbutamide and tolazamide. The effect is perinatal and believed to be directly related to the pharmacologic (hypoglycemic) action of GLUCOTROL. In studies in rats and rabbits no teratogenic effects were found. There are no adequate and well-controlled studies in pregnant women. GLUCOTROL should be used during pregnancy only if the potential benefit justifies the potential risk to the fetus.

Because recent information suggests that abnormal blood glucose levels during pregnancy are associated with a higher incidence of congenital abnormalities. many experts recommend that insulin be used during pregnancy to maintain blood glucose levels as close to normal as possible

Nonteratogenic Efrects: Prolonged severe hypoglycemia has been reported in neonates born to mothers who were receiving a sulfonylurea drug at the time of delivery. This has been reported more frequently with the use of agents with prolonged halfilis Nursing Mothers: Since some sulfonylurea drugs are known to be excreted in human milk, insulin therapy should be Ponsidered if nursing is to be continued

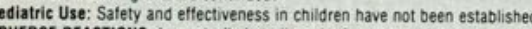

AOVERSE REACTIONS: In controlled studies, the frequency of serious adverse reactions reported was very low. of 02 patients, $11.8 \%$ reported adverse reactions and in only $1.5 \%$ was GLUCOTROL discontinued.

Gertions.

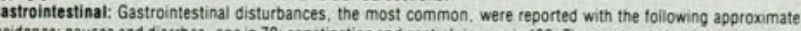

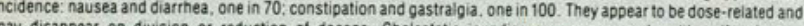
may disappear on division or reduction of dosage. Cholestatic jaundice may occur rarely with sulfonylureas

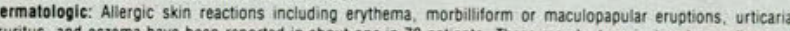

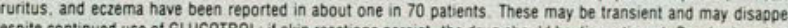
the drug sthould be discontinued. Porphyria cutane tarda and photosensitivity reactions have been reported with sulfonylureas.

Hematologic: Leukopenia, agranulocytosis, thrombocytopenia, hemolytic anemia, aplastic anemia, and pan cytopenia have been reported with sultonylureas.

Metabolic: Hepatic porphyria and disulfiram-like alcohol reactions have been reported with sulfonylureas. Clinica metabolic: Hepatic porphyria and disulfiram-like aicohol reactions have been reported with sulfonylureas.
experience to date has shown that GLUCOTROL has an extremely low incidence of disulfiram-like reactions. Endocrine Reactions: Cases of hyponatremia and the syndrome of inappropriate antidiuretic hormone (SIADH) secretion have been reported with this and other sulfonylureas.

Miscellaneous: Dizziness, drowsiness, and headache have each been reported in about one in fifty patients treated with GLUCOTROL. They are usually transient and seidom require discontinuance of therapy

OVERDOSAGE: Overdosage of sulfonylureas including GLUCOTROL can produce hypogylycemia. If hypogiycemic coma is diagnosed or suspected, the patient should be given a rapid intravenous injection of concentrated $(50 \%)$ glucose solution. This should be folliowed by a continuous infusion of a more dilute (10\%) glucose solution at rate that will maintain the blood glucose at a level above $100 \mathrm{mg}$ ol. Patients should be closely monitored for a minimum of 24 to 48 hours sod gucose at a level abovito from plasma would be prolonged in persons with liver disease. Because of the extensive protein binding of Irom plasma would be prolonged in persons with liver
GLUCOTROL (glipizide). dialysis is unlikely to be of benefit

DOSAGE AND ADMINISTRATION: There is to be of benefit. GLUCOTROL: in general, it should be given approximately 30 minutes betore a meal in postorandial hyperalycemis

Initial Dose: The recommended starting dose is 5 mg betore breaktast: Geritric patients or those wit liver Gisesse may be started $02.5 \mathrm{~m}$. Dosage adjulments should ordinarily be in blood olucose response. At least several days should elapse bet be in inton steps.

Maximum Dose: The maximum recommended total daily dose is $40 \mathrm{mg}$.

Maintenance: Some patients may be effectively controlled on a once-a-day regimen, while others show better response with divided dosing. Total daly doses above $15 \mathrm{mg}$ should ordinarly be divided $5 \mathrm{mg}$ tablet-Pfizer 411 (NDC $5 \mathrm{mg}$ 0049-4110-66) Bottles of 100:10 mo tamolet-Phaped tablets imprinted as follows: Botties of 100

CAUTION: Federal law prohibits dispensing without prescription.

More detailed professional information available on request. care per day and per admission. Catherine G McLaughlin, professor of U-M's School of Public Health, analyzed data from 1972 through 1982 in 25 cities, where the popularity of HMOs has reached as much as 34 percent of the population. She found that on the average, every time the number of participants in an HMO increased by one percentage point, there were increases of $\$ 3.58$ in the average cost of hospital care per patient day, and of $\$ 19.04$ in the average hospital cost per admission. At the same time, however, the total number of annual admissions per 1,000 population fell by 5.79 , and the length of hospital stay declined slightly.

McLaughlin said these results suggest that "when discussing future cost containment strategies, policymakers should consider some form of rate setting, the one factor that seemed to be associated with lower cost per capita."

\section{A naturally occurring chemical found in fruits} and vegetables may reduce the risk of skin cancer by decreasing the activity of Cytochrome P450-dependent enzymes that metabolize carcinogens in that organ. This is the result of experimental animal studies using ellagic acid, according to David Bickers, M.D., professor and chairman of the Department of Dermatology at the Case Western Reserve University School of Medicine.

This latest study shows that skin is a surprisingly active site for the metabolism of a variety of internal and external chemicals. "There is enzymatic activity in the skin that is capable of converting certain inert chemical environmental pollutants into reactive metabolites that can bind to structures in the skin, such as DNA. This enzyme-mediated reaction may initiate cancer," Dr. Bickers said. Initial studies showed that ellagic acid, derived from naturally occurring tannins, inhibits cancer by diminishing this metabolite binding. "We also showed that they could directly inhibit the ability of the enzymes that generate reactive metabolites," he continued.

Although the researchers are a long way from making any recommendations, they say it is conceivable that the repetitive use of substances like ellagic acid or its derivatives, which would reduce the metabolism of carcinogens, would be useful in diminishing the risk of cancer development.

A bed partner could save your life, especially if you're over age 60 . Another person is often pivotal in noticing a major "hidden" sleep disorder. Although its episodes can even occur hundreds of times each night, the victims themselves may be 


\section{Oh, the extremes people go to.}

Some people will go to any length to relieve back pain. Even if it means turning their world upside down.

Too bad she didn't come to you. Relief of painful musculoskeletal conditions can be so simple with Norflex ${ }^{\circledR}$ (orphenadrine citrate) - just one tablet b.i.d. Or one Norflex Injectable for on-the-spot relief.

Norflex effectively relieves pain and associated spasm. And it has a better safety profile - no sedation, ${ }^{*}$ no danger of habituation.

*Some patients may experience transient episodes of light-headedness, dizziness or syncope, which may impair their ability to engage in potentially hazardous activities such as operating machinery or driving a motor vehicle; ambulatory patients should therefore be cautioned accordingly.

\section{NORFLEX BIID.}

(orphenadrine citrate) $\begin{gathered}\text { Sustained-Release } \\ \text { Tablets }\end{gathered}$

\section{Relief pure and simple.}

Please see next page for full

prescribing information. 


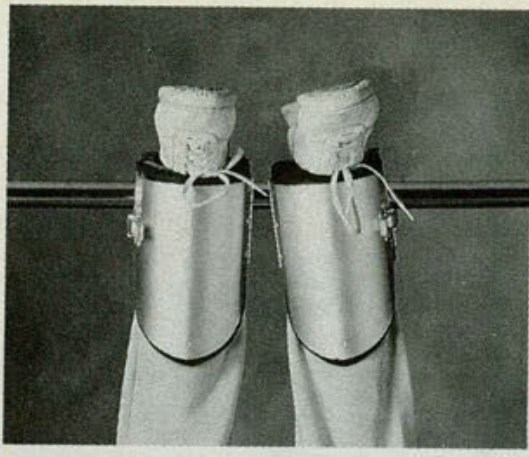

NORFLEX BI.D.

(orphenadrine citrate) taBLets and INJectable

\section{Relief pure and simple.}

\section{Prescribing Information}

DESCRIPTION: Orphenadrine citrate is the citrate salt of orphenadrine (2-dimethylaminoethyl 2-methylbenzhydryl ether citrate). It occurs as a white crystalline powder having a bitter laste. It is practically odorless sparingly soluble in water, slightly soluble in alconol.

ACTIONS: The mode of therapeutic action has not been clearly identified, but may be related to its analgesic properties. Orphenadrine citrate also possesses anticholinergic actions.

NDICATIONS: Orphenadrine citrate is indicated as an adjunct to rest, physical therapy, and other measures for the relief of discomfort associted with acute painful musculoskeletal conditions. The mode of action of the drug has not been clearly identified, but may be related to its analgesic properties. Orphenadrine citrate does not directly relax tense keletal muscles in man

CONIRAINDICATIONS: Contraindicated in patients with glaucoma pyloric or duodenal obstruction, stenosing peptic ulcers, prostatic hypertrophy or obstruction of the bladder neck, cardiospasm (megaesophagus) and myasthenia gravis.

Contraindicated in patients who have demonstrated a previous hyper. sensitivity to the drug.

WARNINGS: Some patients may experience transient episodes of lightheadedness, dizziness or syncope. Norflex may impair the ability of the patient to engage in potentially hazardous activities such as operating machinery or driving a motor vehicle; ambulatory patients should therefore be cautioned accordingly.

USAGE IN PREGNANCY: Sale use of orphenadrine has not been established with respect to adverse effects upon fetal development. Therefore, Norflex should be used in women of childbearing potential and particularly during early pregnancy only when in the judgment of the physician the potential benefits outweigh the possible hazards.

USAGE IN CHILDREN: Safety and effectiveness in children have not been established; therefore, this drug is not recommended for use in the pediatric age group

PRECAUTIONS: Confusion, anxiety and tremors have been reported in few patients receiving propoxyphene and orphenadrine concomitantly. As these symploms may be simply due to an additive effect, reduction of dosage and/or discontinuation of one or both agents is recommended in uch cases.

Orphenadrine citrate should be used with caution in patients with tachycardia, cardiac decompensation, coronary insufficiency, cardiac arrihythmias.

Satety of continuous long-term therapy with orphenadrine has not been established. Therefore, if orphenadrine is prescribed for prolonged use, periodic monitoring of blood, urine and liver function values is recommended

ADE due to the mild anticholinergic action of orphenadrine, and are usually associated with higher dosage. Dryness of the mouth is usually the first

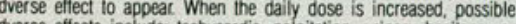
averse ellects include. lachycardia, palpilation, urinary hesilancy or weakness, nausea vomiting headache, dizziness, conlar tension, drowsiness, hypersensitivity reactions, pruritus, hallucinations ton tremos, hypersensitivily reactions, pruritus, halucinations, agitaIntrequently an elderly patient may experience and ocher dermaloses. contusion , an elderly patient may experience some degree of mental con in so forphentione been established

Deen eslablished. th the intramuscular in DOSAGE AMD ADMINISTRATIOH: TABjectable

Adults-Two tablets per day, one in the morning and one in the evening

INUECTABLE: Adults $-0.2 \mathrm{ml}$ ampul $(60 \mathrm{mg})$ intravenously of intramuscularly; may be repeated every 12 hours. Relief may be mainained by 1 Norflex tablet wice daily

HOW SUPPLIED: TABLETS: Bottles of 100 (NDC 0089-0227-10) and 500 (NDC 0089-0221-50), each tablet containing $100 \mathrm{mg}$. of orphenadrine citrate

INJECTABLE: Boxes of 6 (NDC 0089-0540-06) and 50 (NDC 0089.50) $2 \mathrm{mi}$. ampuls, each ampul containing $60 \mathrm{mg}$. of orphenadrine citrate in aqueous solution, made isotonic with sodium chloride. A.M.FS. Category 12:08

CAUTION: Federal law prohibits dispensing without prescription

unaware of the disorder.

Sleep apnea causes repeated halts in breathing during sleep that last from 10 to 180 seconds each. It is most common in the elderly and in overweight middle-aged and older men who snore, and it usually worsens with increasing body weight and advancing age. Sleep apnea not only interrupts the flow of sleep, but it can be fatal if unchecked, especially in older persons who already have heart disease or hypertension.

Unfortunately, even if a person over 60 is not burdened with sleep apnea, sleep is found to be different from that of early adulthood. An estimated 90 percent of Americans between the ages of 60 and 80 complain that they experience chronic or occasional sleeplessness, making the elderly the largest age group with insomnia. Some factors that can interfere with a good night's sleep include physical and mental illness, evening use of alcohol, caffeine, nicotine, and dependence on nightly sleeping pills to invite drowsiness. Changes in routine and life-style, such as retirement, or changes in environment, particularly institutionalization in a hospital or nursing home, can also induce insomnia.

For more information about insomnia, the booklet, "What you should know about insomnia," is available by writing to: Insomnia/Upjohn, Department FS, P.O. Box 307, Coventry, Connecticut 06238. For the location of nearby sleep disorder centers, write to: Association of Sleep Disorders Centers, P.O. Box 2604, Del Mar, California 92014.

A new strategy for locating and monitoring hidden tumors has been devised by scientists at The University of Texas Health Science Center at Dallas. David Ranney, M.D., director of the Laboratory of Targeted Diagnosis and Therapy, report that by using a special dye, known as Gd-DTPA-dextran, researchers have been able to improve the effectiveness of MRI at locating tumors hidden in the body and at observing the action of anti-cancer drugs on tumors.

Gd-DTPA-dextran is a non-toxic, magnetic polymer, which is readily detectable by the MRI scanner and remains in the bloodstream except around tumors. Since tumors have leaky, porous blood vessels, when the dye reaches the tumor, it leaks through the blood vessels and is readily detected by the scanner. The tumor-imaging dye allows identification of tumor structures as small as half a millimeter in diameter. GD-DTPA-dextran also enables physicians to see quickly if a drug is killing all or only part of a tumor.

Dr. Ranney predicts that if current testing goes well, Gd-DTPA-dextran could be approved for use in hospitals within three years.

continued on page 411/76 


\section{GIVE YOUR ANGIMA PAIIENTS

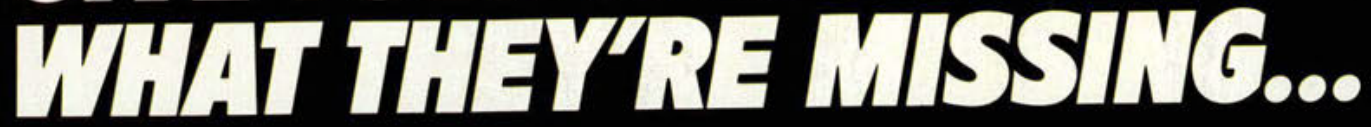

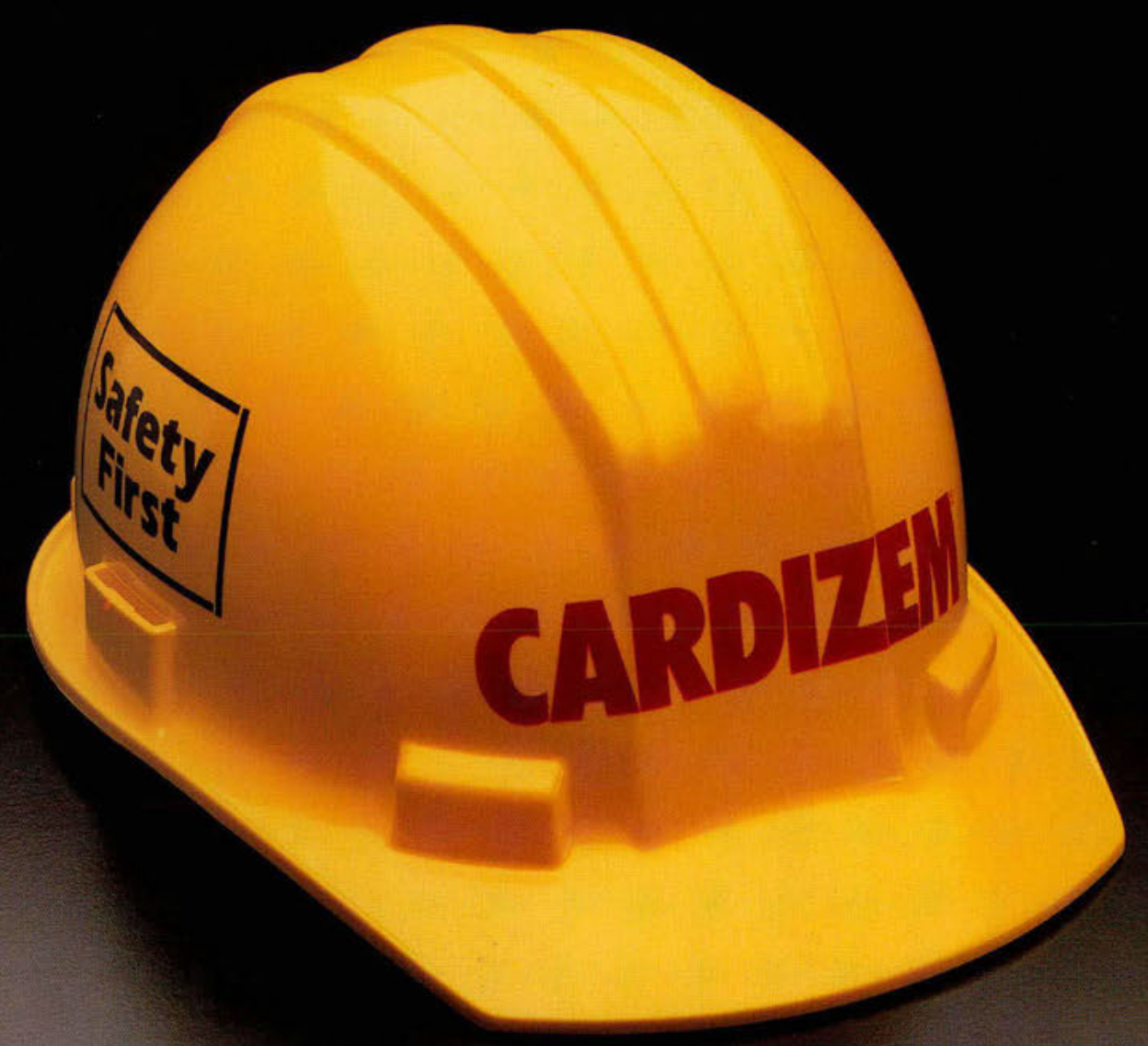

CARDHAW diltiazem HCl/Marion 

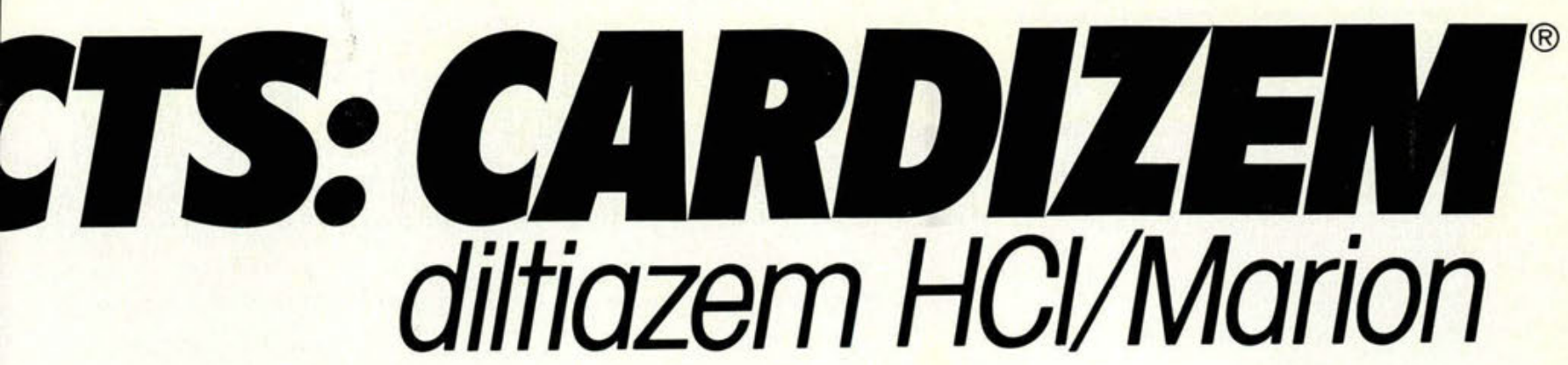

Antianginal action includes dilatation of coronary arteries, a decrease in vascular resistance/ afterload, and a reduction in heart rate

Proven efficacy when used alone in angina'

Compatible with other antianginals ${ }^{2,3 *}$

A safe choice for angina patients with coexisting hypertension, asthma, COPD, or PVD 4.5

* See Warnings and Precautions.

Please see brief summary of prescribing information on the next page.
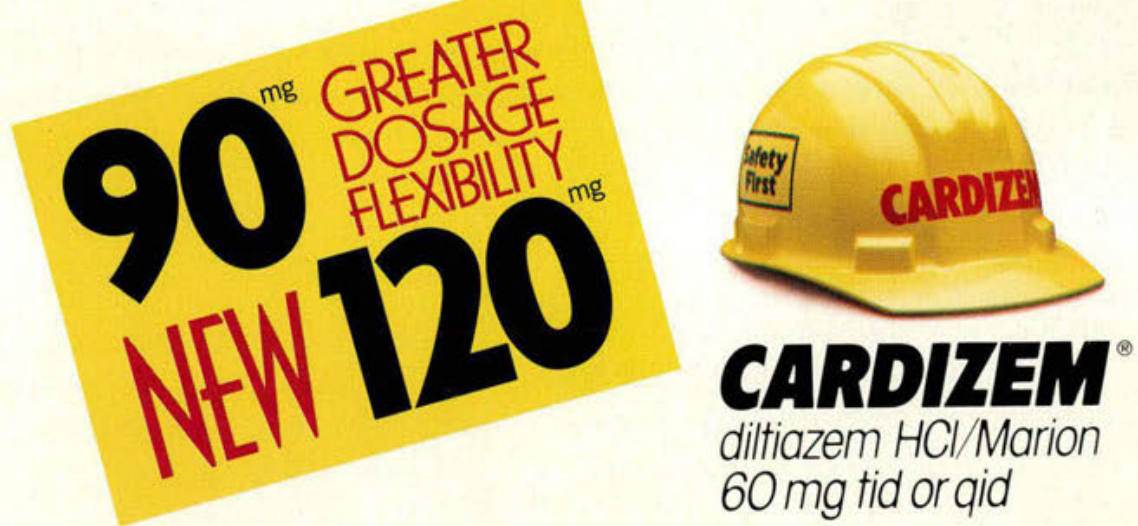


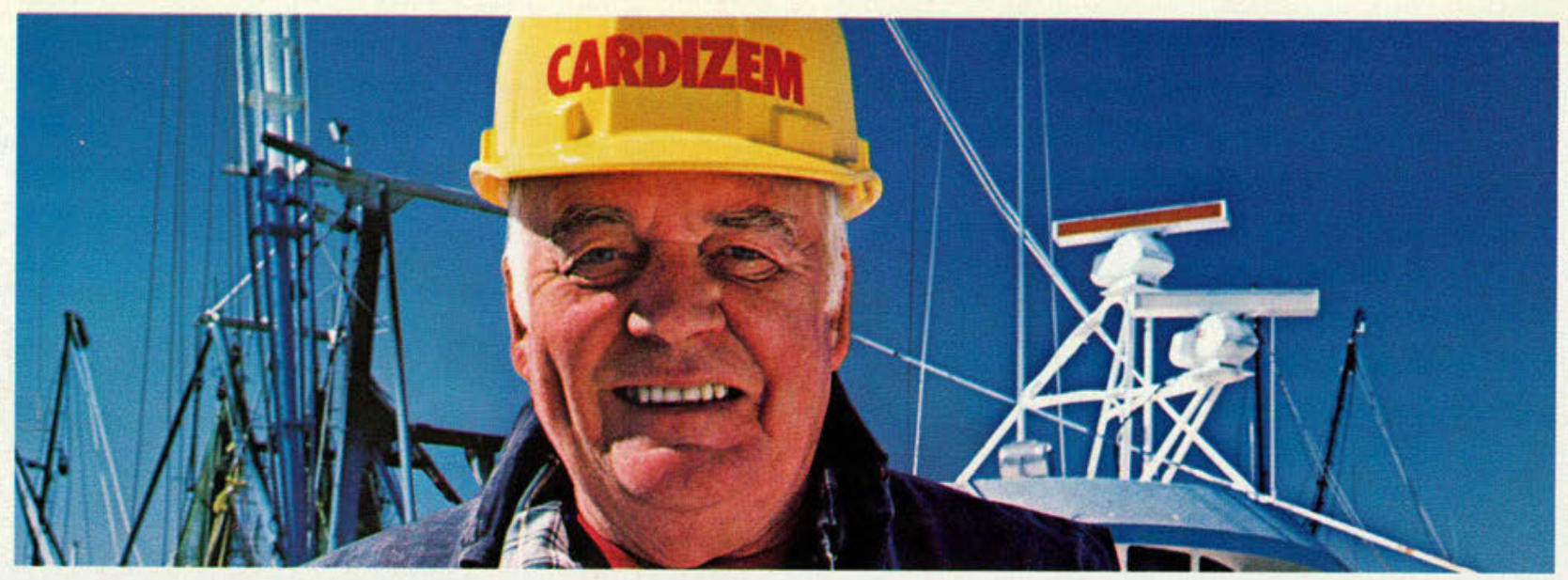

\section{CIRDVAFM FEW SIDE EFFECTS diltiazem HCl/Marion IN ANTIANGINAL THERAPY}

\section{$60 \mathrm{mg}$ tid or qid}

Brief Summary

Professional Use Information

\section{CARDIZEM:}

(diltiazem HCl) $30 \mathrm{mg}$ and $60 \mathrm{mg}$ Tablets

\section{CONTRAINDICATIONS}

CARDIZEM is contraindicated in (1) patients with sick sinus syndrome except in the presence of a functioning ventricular pacemaker, (2) patients with second-or third-degree AV block except in the presence of a functioning ventricular pacemaker, and (3) patients with hypotension (less than $90 \mathrm{~mm} \mathrm{Hg}$ systolic).

\section{WARNINGS}

Cardiac Conduction. CARDIZEM prolongs AV node refractory periods without significantly prolonging sinus node recovery time, except in patients with sick sinus syndrome. This effect may rarely result in abnormally slow heart rates (particularly in patients with sick sinus syndrome) or second- or third-degree AV block (six of 1,243 patients for $0.48 \%$ ). Concomitant use of diltiazem with beta-blockers or digitalis may result in additive effects on cardiac conduction. A patient with Prinzmetal's angina developed periods of asystole ( 2 to 5 seconds) after a single dose of $60 \mathrm{mg}$ of diltiazem.

2. Congestive Heart Failure. Although diltiazem has a negative inotropic effect in isolated animal tissue preparations, hemodynamic studies in humans with normal ventricular function have not shown a reduction in cardiac index nor consistent negative effects on contractility $(d p / d t)$.

Experience with the use of CARDIZEM

alone or in combination with beta-blockers in patients with impaired ventricular function is very limited. Caution should be exercised when using the drug in such patients.

3. Hypotension. Decreases in blood pressure associated with CARDIZEM therapy may occasionally result in symptomatic hypotension.

4. Acute Hepatic Injury. In rare instances, significant elevations in enzymes such as alkaline phosphatose, CPK, LDH, SGOT, SGPT, and other symptoms consistent with acute hepatic injury have been noted. These reactions have been reversible upon discontinuation of dnig therapy. The relationship to CARDIZEM is uncertain in most cases, but probable in some. (SEe PRECAUTIONS.

\section{PRECAUTIONS}

General. CARDIZEM (dilfiazem hydrochloride) is extensively metabolized by the liver and excreted by the kidneys and in bile. As with any new drug given over prolonged periods, laboratory parameters should be monitored at regular intervals. The drug should be used with coution in patients with impaired renal or hepatic function. In subacute and chronic dog and rat studies designed to produce toxicity, high doses of diltiazer were assaciated with hepatic damage In special

subacute hepatic studies, oral doses of $125 \mathrm{mg} / \mathrm{kg}$ and higher in rats were associated with histological changes in the liver which were reversible when the drug was discontinued. In dogs, doses of $20 \mathrm{mg} / \mathrm{kg}$ were also associated with hepatic changes; however, these changes were reversible with continued dosing.

Drug Interaction. Pharmacologic studies indicate that there may be additive effects in prolonging AV conduction when using beta-blockers or digitalis concomitantly with CARDIZEM. (SEe WARNINGS.)

Controlled and uncontrolled domestic studies suggest that concomitant use of CARDIZEM and beto-blockers or digitalis is usually well folerated. Available data are not sufficient, however, to predict the effects of concomitant treatment, particularly in patients with left ventricular dysfunction or cardiac conduction abnormalities. In healthy volunteers, dilfiazem has been shown to increase serum digoxin levels up to $20 \%$

\section{Carcinogenesis, Mutogenesis, Impoiment of}

Fertility. A 24-month study in rats and a 21 -month study in mice showed no evidence of carcinogenicity. There was also no mutagenic response in in vitro bacterial

test's. No intrinsic effect on fertility was observed in rats.

Pregnancy. Category C. Reproduction studies have been conducted in mice, rats, and rabbits. Administration of doses ranging from five to ten fimes greater (on a $\mathrm{mg} / \mathrm{kg}$ basis) than the daily recommended therapeutic dose has resulted in embryo and fetal lethality. These doses, in some studies, have been reported to cause skeletal abnormalifies. In the perinatol posinatal studies, there was some reduction in early individual pup weights and survival rates. There was an increased incidence of stillbirths at doses of 20 times the human dose or greater.

There are no well-controlled studies in pregnant women; therefore, use CARDIZEM in pregnant women only if the potential benefit justifies the potential risk to the fetus

Nursing Mothers. Dilliazem is excreted in human milk. One report suggests that concentrations in breast milk may approximate serum levels. If use of CARDIZEM is deemed essential, an alternative method of infant feeding should be instituted.

Pediatric Use. Sofety and effectiveness in children have not been established.

\section{ADVERSE REACTIONS}

Serious adverse reactions have been rare in studies carried out to date, but it should be recognized that patients with impaired ventricular function and cardiac conduction abnormalities have usually been excluded.

In domestic placebo-controlled trials, the incidence of adverse reactions reported during CARDIZEM therapy was not greater than that reported during placebo therapy. The following represent occurrences observed in clinical studies which can be at least reasonably asso ciated with the pharmocology of calcium influx inhibition In many cases, the relationship to CARDIZEM has not been established. The most common occurrences as well as their frequency of presentation are: edema (2.4\%) heodache $(2.1 \%)$, nausea (1.9\%), dizziness (1.5\%), rash (1.3\%), asthenia (1.2\%). In addition, the following events were reported infrequently (less than $1 \%$ )

Cardiovascular: $\quad$ Angina, arthythmia, AV block (first degree), AV block (second or thire degree - see conduction warning) bradycardia, congestive hear foilure, flushing, hypotension, polpitotions, syncope.

Nervous System: Amnesia, gait abnormality, hallucinations, insomnia, nervousness, paresthesia, personality change somnolence, finnitus, tremor.

Gastrointestinal: Anorexia, constipation, dianthea dysgeusia, dyspepsia, mild elevations of alkaline phosphotose, SGOT, SGPT, and LDH (see hepatic warnings), vomiting, weight

Dermatologic: Petechioe, pruritus, photosensitivity,
urticaria.

Other: $\quad$ Amblyopia, dyspnea, epistaxis, eye imitation, hyperglycemia, nasal congestion, nocturia, ostecarticular pain, polyuria, sexual difficulties.

The following postmarketing events have been reported infrequently in patients receiving CARDIZEM: alopecia, gingival hyperplasia, erythema multiforme, and leukopenia. However, a definitive cause and effect between these events and CARDIZEM therapy is yet to be estoblished. Issued 7/86 See complete Professional Use Information before prescribing.

References: 1. Pepine W, Feldman RL, Hill JA ef a Clinical outcome after treatment of rest angina with calcium blockers: Comparative experience during the initial vear of theropy with diltiazem, nifedipine, and verapamil Am Heart J 1983: 106 (6) 1341-1347 2. Shapiro W: Calcium channel blockers: Actions on the heart and uses in ischemic heart disease. Consultant 1984:24(Dec): 150-159. 3. Johnston DL, Lesoway R Humen DP et al: Clinical and hemodynamic evaluation of propranolol in combination with verapamil, nifedipine and dilfiazem in exertional angina pectoris: A placebocontrolled, double-blind, randomized, crossover study. Am J Cardiol 1985;55:680-687. 4. Cohn PF, Braunwald E: Chronic ischemic heart disease, in Brounwald E (ed) Heart Disease: A Textbook of Cardiovascular Medicine. ed 2. Philadelphia. WB Saunders Co, 1984, chap 39 5. Schroeder JS: Calcium and beto blockers in ischemic heart disease: When to use which. Mod Med 1982,50(Sept):94-116. 


\section{American Osteopathic Association \\ Continuing Medical Education}

\section{CERTIFICATION OF HOME STUDY}

his is to certify that I,

tivity for AOA CME credits.

completed the following

Please print

pe of activity (such as reading or listening)

ame of journal(s) or audio-tape and date(s) of issue(s):

(One-half CREDIT may be granted for each issue or tape)

AAIL TO: AOA Division of CME, 212 East Ohio Street, Chicago, Illinois 60611

EEP A DUPLICATE FOR YOUR RECORDS!

The Home Study form is intended to document individual reading of recognized scientific journals, listening to approved audio-tapes, and other approved home study courses and programs under the criteria described for Category 2-B.

Only one type of home study, such as reading, should be indicated on a single form, though multiple issues of scientific journals may be listed.

This form should not be used, however, when CME quiz cards for the AOA Journal are submitted separately.

\begin{tabular}{|l|}
\hline FOR OFFICE USE ONLY \\
\hline Cat. $\_$Credits \\
Program \# $\#$ 2-B \\
Doctor \# \\
Doctor's Name
\end{tabular}

Please refer to the revised CME GUIDE for additional information. 
The newly recognized threat of radon gas in homes, believed to be a risk factor for lung cancer in the general population, has prompted scientists to evaluate the extent of the health hazard. National Cancer Institute (NCI) investigators and collaborating scientists are currently conducting three epidemiologic studies to assess the health risks of residential radon on populations in New Jersey, Sweden, and China. The studies are expected to be completed in about two years.

Radon is one of the world's most widely distributed natural carcinogens. The Environmental Protection Agency estimates that each year, between 5,000 and 30,000 lung cancer deaths in the United States may be attributed to radon. Recent measurements of radon in homes in various parts of the United States have shown that high levels of the gas can accumulate inside of houses built on uranium-rich soil. The invisible, odorless gas moves through small spaces in soil and rock and seeps into homes through dirt floors, cracks in concrete, floor drains, sump joints, and water drawn in from private wells. Lack of ventilation and tight insulation may contribute to indoor radon gas buildup. John Boice, M.D., chief of the NCIs Radiation Epidemiology Branch, believes that these studies will yield important information on radon risk, including information on the possible interaction of radon with cigarette smoking and the pattern of risk over time.

\section{An artificial ligament that attaches between} the thigh and lower leg bone has been approved for marketing by the Food and Drug Administration (FDA). The braided strand of synthetic fiber stabilizes the knee after the anterior cruciate ligament is torn-a common injury in football, soccer, and skiing.

The Gore-Tex (W. Gore and Associates, Flagstaff, Arizona) ligament has been used experimentally on more than 1,000 patients at 27 hospitals in the United States, some of which have been followed for two years. After the device is implanted, many patients are able to walk in several weeks, as compared to the six or eight months after traditional tendon grafting surgery.

At this time, the artificial ligament is approved only for patients in whom tendon grafting has failed. The indications could be broadened as more clinical experience accumulates. Since the FDA presently has data on the performance of the ligament for only the two-year period, the agency will require the manufacturer to continue to study a group of patients for up to 5 years after implantation to confirm long-term safety and effectiveness of the device.

\section{Proposed Amendment to the Bylaws of the American Osteopathic Association}

At its meeting on May 27, 1987, the AOA Committee on Membership recommended the following addition to the AOA Bylaws for consideration by the AOA House of Delegates at its July, 1987 meeting:

\section{HONORARY MEMBERSHIP}

Honorary Members. By specific action of the Board of Trustees, or its Executive Committee, honorary membership may be granted to individuals, not eligible for any other category of membership, who support the goals and objectives of this Association. Such honorary members shall not be required to pay dues or assessments. They shall receive complimentary copies of the Association's publications and such other services as authorized by the Board of Trustees.

Honorary members shall not be eligible to membership in the House of Delegates or the Board of Trustees, or hold any elective offices of this Association. Special listing in the YEARBOOK AND DIRECTORY shall be provided.

Such membership, when conferred, shall remain in full force and effect unless revoked by action of the Executive Committee or Board of Trustees of the American Osteopathic Association. 


\section{Allergy Relief}

\section{Knows No Boundaries}
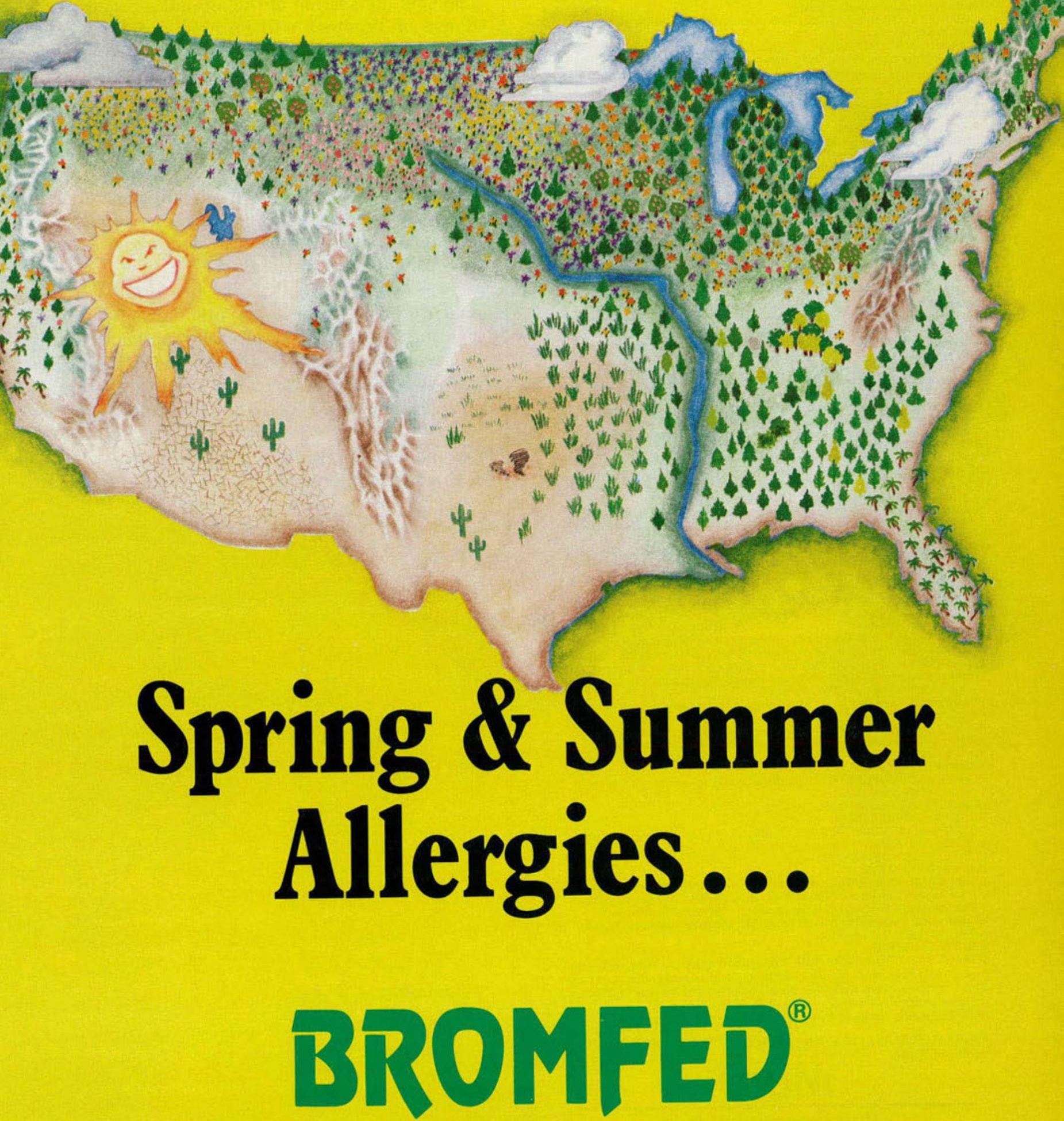


\section{Official call}

\section{Prescribe}

BROMFED $^{\circledR}$ -

BROMFED-PD ${ }^{\circledR}$

Timed-release Capsules

(antihistamine/decongestant action)

BROMFED ${ }^{*}$ CAPSULES Timed-release capsules

(antihistamine/decongestant action)

DESCRIPTION: A light green and clear capsule containing white beads. Each capsule contains:

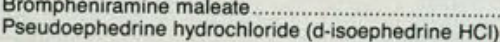

BROMFED-PD ${ }^{\circ}$ CAPSULES Timed-release capsules

(antihistamine/decongestant action)

DESCRIPTION: A dark green and clear capsule containing white beads. Each capsule contains:

Brompheniramine maleate

Pseudoephedrine hydrochloride (d-isoephedrine $\mathrm{HCl}$ ) _.................... $6 \mathrm{mg}$ Both products are in a specially prepared base to provide prolonged action. BROMFED TABLETS

DESCRIPTION: A white scored tablet. Each tablet contains:

Brompheniramine maleate .............................................................. $4 \mathrm{mg}$

These products contain ingredients of the following therapeutic classes;

antihistamine and decongestant.

CLINICAL PHARMACOLOGY: Brompheniramine maleate is an alkylamine type antihistamine. This group of antihistamines are among the most active histamine antagonists and are generally effective in relatively low doses. The drugs are not so prone to produce drowsiness and are among the most suitable agents for day time use; but again, a significant proportion of patients do experience this effect. Pseudoephedrine hydrochloride is a sympathomimetic which acts predominatly on which acts predominantly on alpha receptors and has littie action on beta receptors. It therefore functions as an oral nasal decongestant with minimal

INDICATIONS: For the treatment of the symptoms of seasonal and perennial allergic rhinitis, and vasomotor rhinitis, including nasal obstruction (congestion) CONTRAINDICATIONS: Hypersensitivity to any of the ingredients. Also contraindicated in patients with severe hypertension, severe coronary artery disease, patients on MAO inhibitor therapy, patients with narrow-angle glaucoma, urinary retention, peptic ulcer and during an asthmatic attack. BROMFED /BROMFED-PD

WARNINGS: Considerable caution should be exercised in patients with hypertension, diabetes mellitus, ischemic heart disease, hyperthyroidism, increased intraocular pressure and prostatic hypertrophy. The elderly (60 years or older) are more likely to exhibit adverse reactions.

Antihistamines may caly to exhibit adverse reactions.

Antihistamines may cause excitability, expecially in children. At doses higher than the recommended dose, nervousness, dizziness or sleeplessness may

PRECAUTIONS: General: Caution should be exercised in patients with high blood pressure, heart disease, diabetes or thyroid disease. The antihistamine in this product may exhibit additive effects with other CNS depressants, including alcohol

INFORMATION FOR PATIENTS: Antihistamine may cause drowsiness and ambulatory patients who operate machinery or motor vehicles should be cautioned accordingly.

DRUG INTERACTIONS: MAO inhibitors and beta adrenergic blockers increase the effects of sympathomimetics. Sympathomimetics may reduce the antihypertensive effects of methyldopa, mecamylamine, reserpine and veratrum alkaloids. Concomitant use of antihistamines with alcohol and other CNS depressants may have an additive effect.

PREGNANCY: The safety of use of this product in pregnancy has not been established

ADVERSE REACTIONS: Adverse reactions include drowsiness, lassitude, nausea, giddiness, dryness of mouth, blurred vision, cardiac palpitations, flushing, increased irritability or excitement (especially in children).

BROMFED CAPSULES

DOSAGE AND ADMINISTRATION: Adults and children over 12 years of age-

1 capsule orally every 12 hours.

HOW SUPPLIED: Bottles of $100-500$

BROMFED-PD ${ }^{*}$ CAPSULES

DOSAGE AND ADMINISTRATION: Children 6 to 12 years of age -1 capsule

every 12 hours. Adults -2 capsules every 12 hours.

HOW SUPPLIED: Bottles of $100-500$

HOW SUPPLIED: Bottles

\section{DOSAGE AND ADMINISTP}

DOSAGE AND ADMINISTRATION: Adults and children 12 and over: One tablet every 4 hours not to exceed 6 doses in 24 hours. Children 6 to 12 years: Onehalf tablet every 4 hours not to exceed 6 doses in 24 hours. Do not give to children under 6 years except under the advice and supervision of a physician. HOW SUPPLIED: Bottles of 100

BROMFED SYRUP

DOSAGE AND ADMINISTRATION: Adults and children 12 years of age and over: 2 teaspoonfuls orally every $4-6$ hours. Children 6 to under 12 years of age: 1 teaspoon orally every $4-6$ hours. Do not exceed 4 doses in 24 hours. Children under 6 years of age, consult a physician.

HOW SUPPLIED: Bromfed Syrup is available in $16 \mathrm{fl}$. oz. bottles.

CAUTION: FEDERAL (U.S.A.) LAW PROHIBITS DISPENSING WITHOUT A PRESCRIPTION
To the officers and members of the American Osteopathic Association:

You are hereby notified that the annual meeting of the American Osteopathic Association will be held in Chicago, Illinois, on July 23-27, 1987, at the Chicago Marriott Hotel.

The opening session of the annual meeting of the Board of Trustees will be held at 9:00 a.m. on Thursday, July 23.

The House of Delegates will convene for the annual business session of the association at 10:00 a.m. on Sunday, July 26. All meetings of the House of Delegates will be held at the Chicago Marriott Hotel. The Committee on Credentials will register delegates and alternate delegates beginning at 8:30 a.m. on Sunday, July 26 . The House will conclude its session on Monday, July 27.

At least 30 days prior to the first day of the annual meeting, the secretary of each divisional society must certify to the executive director of the American Osteopathic Association a list of the names and addresses of delegates and alternate delegates.

Eugene L. Sikorski, D.O., President

T. Eugene Zachary, D.O., Speaker of the House 